\title{
Effect of coffee and a cola-based soft drink on the color stability of bleached bovine incisors considering the time elapsed after bleaching
}

\author{
Rodrigo PIROLO', Rafael Francisco Lia MONDELLI², Gisele Maria CORRER ${ }^{3}$, Carla Castiglia GONZAGA ${ }^{3}$, Adilson \\ Yoshio FURUSE ${ }^{2}$
}

\author{
1- Private practice, Curitiba, PR, Brazil. \\ 2- Department of Operative Dentistry, Endodontics and Dental Materials, Bauru School of Dentistry, University of São, Paulo, Bauru, SP, Brazil. \\ 3- Graduate Program in Dentistry, Positivo University, Curitiba, PR, Brazil.
}

Corresponding address: Adilson Yoshio Furuse - Departamento de Dentística, Endodontia e Materiais Odontológicos - Faculdade de Odontologia de Bauru, Universidade de São Paulo - Alameda Dr. Octávio Pinheiro Brisolla, 9-75 - Bauru - SP - Brazil - 17012-901 - Phone: +55 $143235-8323$ - Fax: +55 14 3235 8523 - e-mail: furuse@usp.br

Submitted: November 8, 2013 - Modification: April 28, 2014 - Accepted: May 28, 2014

\section{ABSTRACT}

\begin{abstract}
TTe here is no consensus about the waiting time necessary for the patient to start consuming beverages containing colorants again after bleaching. Objective: To evaluate the influence of beverages with coloring agents on bleached bovine incisors considering the time elapsed after bleaching. Material and methods: Sixty bovine incisors were bleached with $35 \%$ hydrogen peroxide for in-office use (Whiteness HP Max) and divided into 10 groups. The color was evaluated with a spectrophotometer (Spectro Shade MICRO) before and after bleaching, employing the CIE-Lab system. After bleaching, the teeth were exposed for $5 \mathrm{~min}$ to coffee or cola-based soft drink (CBSD) at different periods after bleaching: $10 \mathrm{~min}, 1 \mathrm{~h}, 24 \mathrm{~h}, 48 \mathrm{~h}$, and $72 \mathrm{~h}$. Color $(\Delta \mathrm{E})$ and lightness $(\Delta \mathrm{L})$ variations were obtained from the CIE-Lab coordinates. Data were subjected to two-way ANOVA and Tukey HSD tests $(p<0.05)$. Results: Significant differences were observed between groups for both the $\Delta \mathrm{L}$ and $\Delta \mathrm{E}$ values $(\mathrm{p}<0.001)$. All specimens presented a decrease in brightness (negative $\Delta \mathrm{L}$ ). The highest $\Delta \mathrm{E}$ values were observed for teeth stained with a CBSD at 10 min and $1 \mathrm{~h}$ (4.12 and 4.16, respectively). Teeth pigmented with coffee presented $\Delta \mathrm{E}$ values below 3.3 units for all evaluation times. Conclusion: The exposure to coffee after bleaching causes less color changes than the exposure to a CBSD regardless of the time after bleaching.
\end{abstract}

Keywords: Tooth bleaching. Bleaching agents. Color.

\section{NTRODUCTI ON}

The search for optimal aesthetics of the smile is increasingly present in dental offices. This increased demand for cosmetic procedures may be slightly influenced by the media, since it depicts the beauty of white teeth, always with perfect shape and alignment ${ }^{15}$. Among other cosmetic treatments, tooth whitening is one of the most requested because it is a low-cost and fast procedure. Moreover, the various techniques available are safe and well described in the literature ${ }^{15,18}$. However, there are still uncertainties regarding staining after bleaching procedures 2,3,13,17. This concern is mainly related to the time the patient should wait until consuming foods and beverages that contain staining agents.

There are basically two modalities of bleaching treatments for vital teeth: dentist-supervised home bleaching and in-office bleaching. Currently, bleaching agents can be presented as hydrogen peroxide $\left(\mathrm{H}_{2} \mathrm{O}_{2}\right)$, and carbamide ${ }^{10}$. The latter undergoes chemical decomposition releasing $\mathrm{H}_{2} \mathrm{O}_{2}$. Hydrogen peroxide acts primarily by oxi-reduction, making long-chain chromophore molecules smaller and less colorful ${ }^{6}$. The different tooth whitening techniques have the same goal and their results have been proven $9,16,18$. However, certain variables influencing the bleaching procedures are still unknown ${ }^{14,16,26}$. A factor that is suggested in 
influencing the final bleaching outcome is the exposure to staining agents present in foods and beverages ${ }^{11}$. The prolonged exposure to these agents may cause severe discoloration to teeth recently subjected to bleaching procedures. However, it is important to note that foods and beverages are not the only possible staining agents. Tobacco and other drugs may also cause tooth discoloration ${ }^{12,22}$.

Coloring agents are present in most foods. Beverages such as cola-based soft drinks, black tea, coffee and red wine produce a greater influence on the staining of teeth ${ }^{28}$, and the consumption of such beverages is highly popular worldwide. Notably, after tooth whitening procedures, a permanent total ban of these liquids for aesthetic purposes is impractical for most people. Furthermore, it has been observed that susceptibility to staining from dyes is higher after tooth whitening procedures ${ }^{3}$. However, there is a general lack of information regarding the esthetic damage caused by dyes during or shortly after the bleaching treatment in relation to the visual perception of color change. The waiting time necessary for the patient to return to consuming beverages containing colorants must also be assessed in order to avoid an unacceptable color change caused by staining agents.

In colorimetric studies, the color variation $(\Delta \mathrm{E})$ obtained from analysis employing the ClE-Lab (Commission Internationale de l'Eclairage L*, $\left.a^{*}, b^{*}\right)$ color space has been commonly used to specify possible clinical correlations in a way that a $\Delta \mathrm{E}$ value smaller than one unit is not generally identified by observers ${ }^{25}$. When the $\Delta \mathrm{E}$ values are between 1 and 3.3 the difference is perceivable, but generally considered acceptable. This means that although there is a color variation, the difference does not indicate the need of replacement of an esthetic restoration nor the need of repeating the bleaching procedure. On the other hand, when the $\Delta \mathrm{E}$ is over 3.3 units it is considered unacceptable due to the great color difference present ${ }^{23}$. The aim of this study was to investigate the influence of beverages with coloring agents on bleached bovine incisors considering the time elapsed after bleaching. The hypothesis evaluated was that bovine teeth bleached with 35\% hydrogen peroxide would present an unacceptable color difference ( $\Delta E$ above 3.3) when exposed to coloring agents, regardless of the waiting time after bleaching.

\section{MATERI AL AND METHODS}

\section{Selection of teeth}

Sixty bovine incisors were selected for this study. They were pre-selected according to their condition and color. Teeth with significant spots and fractures were eliminated from the set. From the extraction in the slaughterhouse until the tests, each tooth was stored in $0.5 \%$ chloramine $\mathrm{T}$ and at no time suffered dehydration. Each specimen was properly cleaned with Robson prophylaxis brush, pumice and water for $40 \mathrm{~s}$ across the labial surface under manual pressure on a low-speed contra angle. After cleaning, the teeth were stored in distilled water at $37^{\circ} \mathrm{C}$ for no more than 3 days before bleaching procedures.

Maintenance of temperature and humidity

In order to maintain the temperature and humidity of the teeth during the bleaching procedures, a special device consisting of two plastic trays of different sizes, a pump, a thermostat and a heater, was assembled (Figure 1 ). The largest tray $(54 \mathrm{~cm} \times 38 \mathrm{~cm} \times 8 \mathrm{~cm}$ ) was used as the main water reservoir. Inside this tray, a smaller one ( 40 $\mathrm{cm} \times 27 \mathrm{~cm} \times 4.5 \mathrm{~cm}$ ) was inserted with its opening facing the bottom of the larger tray. The two diagonal corners of the smaller tray were removed to allow free circulation of water.

Ten one-centimeter-diameter perforations were made at the center of the base of the smallest tray with two centimeters of distance between perforations. The perforations were capped with a rubber dam (Madeitex, São José dos Campos, SP, Brazil). Pen markings were made on the dam in the center of each marking for perforation and the markings were punched with an Ainsworth rubber dam punch (SS White, Rio de Janeiro, RJ, Brazil). Afterwards, the dam was attached to the perforated tray with adhesive tape.

For the circulation and heating, two heaters and a pump were submerged in the water. The pump was installed in a corner of the larger tray. The reservoir had a thermostat to control the temperature and an auxiliary heater to maintain the circulating water temperature constant at $\approx 37^{\circ} \mathrm{C}$. A digital thermometer was also inserted into this system for the visual monitoring of the temperature. During the bleaching procedures, each tooth was inserted into a perforation, with only the root in contact with the circulating water. The crowns were maintained above the rubber dam separation to replicate a clinical condition. Figure 1 shows a schematic representation of the device assembled to maintain the teeth temperature.

\section{Spectrophotometer measurement, bleaching and dying}

Before bleaching, spectrophotometric data of each sample was collected to evaluate the effectiveness of the procedures. For the purpose of standardizing the color analyses, a white rectangular closed-cell foam base was used to stabilize the spectrophotometer and the dental specimen in the same position. This base had 
markings to ensure that the spectrophotometer was aligned to the long axis and amelo-cemental junction of the tooth. Only the center portion of the tooth was used for the collection of data according to the CIE-Lab (Commission Internationale de I'Eclairage L*, a*, b*) color space by the Spectro Shade ${ }^{\mathrm{TM}}$ MICRO (MHT Optic Research AG, Milan, Italy) spectrophotometer. The device was calibrated beforehand, using the white and green standards contained in its rechargeable base. The coordinate system translates the CIE luminosity ( $L^{*}$ ) numerically, and the match in red $\left(+a^{*}\right)$ or green $\left(-a^{*}\right)$ and yellow $\left(+b^{*}\right)$ or blue $\left(-b^{*}\right)$. To obtain the data, the sequence followed these steps: sample visualization, image capture for spectrophotometry, determination of the area to be analyzed, selection of the middle third, and acquisition of the values of L*, a* and b*

After the initial color analysis, distilled water was added to the temperature maintenance system and the temperature was raised to $37^{\circ} \mathrm{C}$. Each intact tooth was inserted into a perforation, with only the root being in contact with the circulating water. The crowns were maintained above the rubber dam separation. The 35\% hydrogen peroxide gel was mixed following the manufacturer's recommendations (Whiteness HP Max, FGM, Joinville, SC, Brazil), and the bleaching gel was applied to the buccal surface and left for 45 min to promote the action of the bleaching agent. The teeth were rinsed in tap water and stored in distilled water. The bleaching procedure was repeated for three consecutive days. At the end of the third day, a color measurement was recorded with the spectrophotometer. This measurement was considered the baseline color analysis.

The groups $(n=6)$ were divided according to the time before being exposed to the drinks. After bleaching, the teeth were exposed to either colabased soft drink (CBSD) (Coca Cola, Curitiba, PR, Brazil) or instant coffee (Nescafé, Nestlé, São Paulo, $\mathrm{SP}$, Brazil) for $5 \mathrm{~min}$. The coffee was prepared according to the manufacturer $>$ s instructions - 100 $\mathrm{ml}$ of water for 2 level teaspoons. The coffee was allowed to cool to a mean temperature of $50^{\circ} \mathrm{C}$ before conducting the experiment. The temperature of the soft drink used was $10^{\circ} \mathrm{C}$. The studied times were $10 \mathrm{~min}, 1 \mathrm{~h}, 24 \mathrm{~h}, 48 \mathrm{~h}$ and $72 \mathrm{~h}$ after bleaching.

The differences (final value minus initial) between the CIE-Lab coordinates ( $\Delta \mathrm{L}^{*}, \Delta \mathrm{a} *$ and $\Delta b^{*}$ ) were calculated for each experimental time. With this information, the value of the color variation $(\Delta \mathrm{E})$ result was determined according to the formula:

$$
\Delta \mathrm{E}=\left[\left(\Delta \mathrm{L}^{*}\right)^{2}+(\Delta \mathrm{a} *)^{2}+\left(\Delta \mathrm{b}^{*}\right)^{2}\right]^{1 / 2}
$$

where $\Delta \mathrm{L}^{*}, \Delta \mathrm{a}^{*}$ and $\Delta \mathrm{b}^{*}$ are the differences in the respective values before and after staining.

In the present study, $\Delta \mathrm{E}$ value was considered clinically undetectable if smaller than 1 unit, clinically acceptable if between 1 and 3.3 and unacceptable if greater than $3.3^{23,25}$.

\section{Statistical analysis}

The data were analyzed by two-way ANOVA and Tukey HSD multiple comparison tests. The type of dye (CBSD and coffee) and the time after bleaching ( $10 \mathrm{~min}, 1 \mathrm{~h}, 24 \mathrm{~h}, 48 \mathrm{~h}$, and $72 \mathrm{~h}$ ) were set as the dependent variables. An overall level of significance of $5 \%$ was adopted. In order to be closer to a normal distribution, experimental times in minutes were log-transformed. Pearson's correlation and linear regression analysis were used to evaluate the relation between the log-time and $\Delta \mathrm{E}$ value.

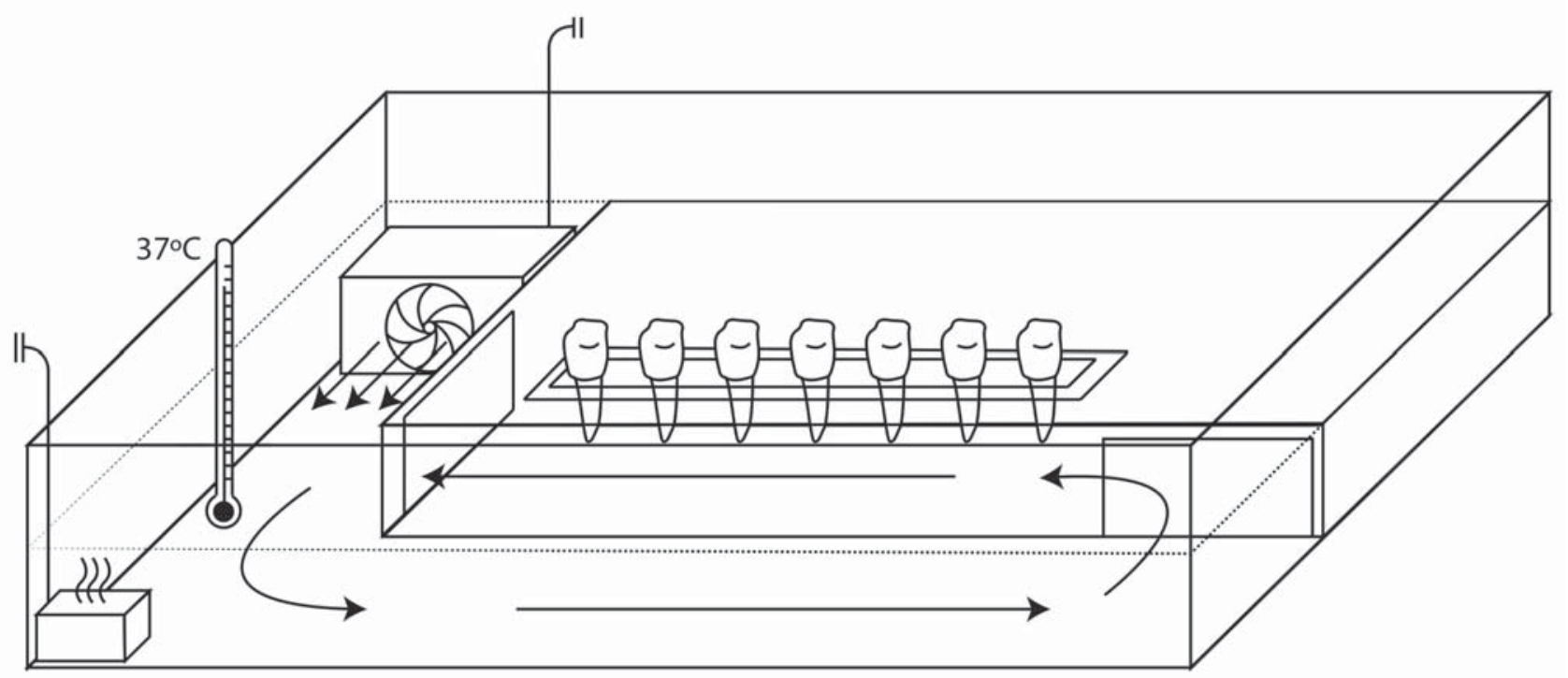

Figure 1- Device assembled to maintain temperature and humidity of teeth during bleaching procedures. The arrows represent the water flow 


\section{RESULTS}

The effectiveness of the bleaching procedures was confirmed by the mean overall $\Delta \mathrm{E}$ value for all bleached teeth $(4.2 \pm 1.3)$. After bleaching, the pigmentation of the teeth had decreased, i.e., a* decreased (less yellow color), showing a negative $\Delta a^{*}$ value $(-0.7 \pm 0.4) ; b^{*}$ decreased (less red color), showing a negative $\Delta b^{*}$ value $(-2.4 \pm 1.2)$ and $L^{*}$ (brightness) increased, with a positive $\Delta L^{*}$ value, with a mean of $3.2 \pm 1.2$.

Means and standard deviations of the $\Delta \mathrm{L}^{*}$ and $\Delta \mathrm{E}$ values after pigmentation are shown in Table 1. All teeth showed a decrease in luminosity (negative value of $\Delta \mathrm{L}^{*}$ ) after being exposed to the evaluated dyes. There were significant differences between the types of dyes $(p<0.0001)$. The time after bleaching had no effect on the decrease of the $\Delta L^{*}$ value $(p<0.074)$. A significant interaction effect between the type of dye and time after bleaching was also observed $(p=0.0002)$. Smaller decreases in $L^{*}$ values occurred when the teeth were exposed to coffee for $10 \mathrm{~min}, 1 \mathrm{~h}$ or $24 \mathrm{~h}$. When considering the $\Delta \mathrm{E}$ values, there were significant differences between the types of dyes $(p<0.0001)$ and time after bleaching $(p=0.008)$. An interaction effect was also observed $(p<0.0001)$. The highest values of $\triangle \mathrm{E}$ were observed in the specimens pigmented with the CBSD. Teeth pigmented with coffee presented a $\triangle E$ value below 3.3 for all times evaluated. As observed in Figure 2, the values of $\triangle E$ tended to decrease over time for the CBSD, while it tended to be constant for coffee. Teeth pigmented with CBSD showed $\triangle \mathrm{E}$ values similar to teeth pigmented with coffee $72 \mathrm{~h}$ after bleaching. All $\Delta \mathrm{E}$ values obtained were higher than one unit and, for this reason, were

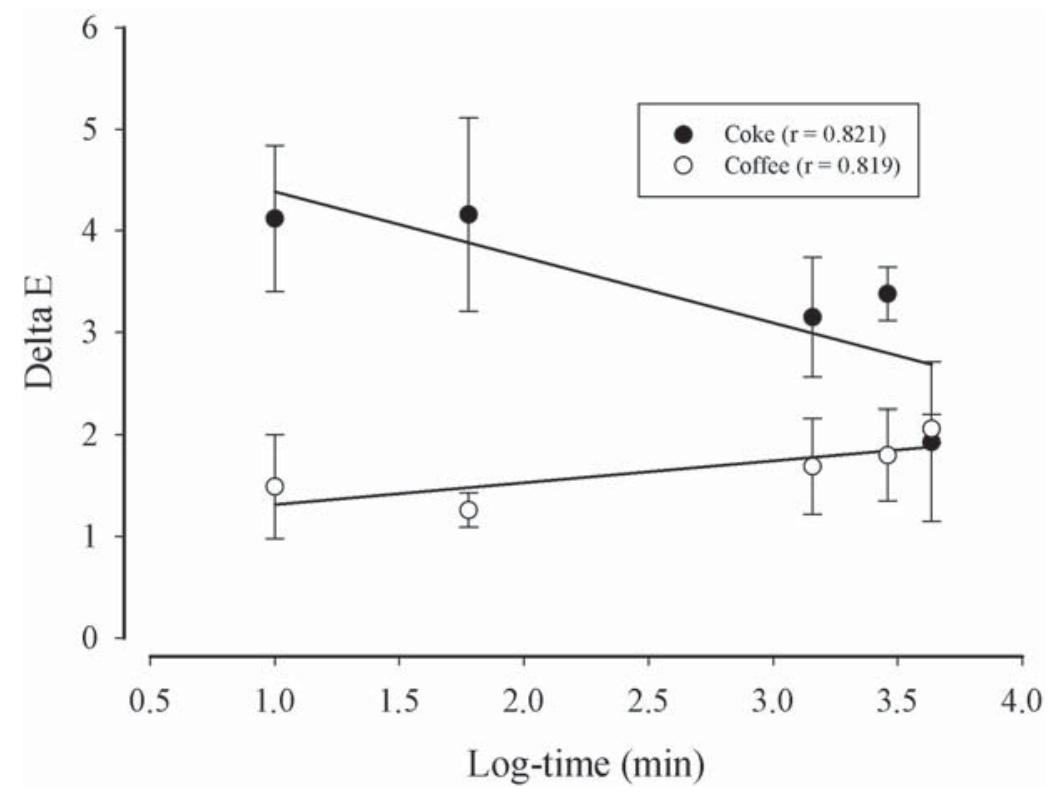

Figure 2- Mean values of $\Delta \mathrm{E}$ as a function of log-time. CBSD= cola-based soft drink

Table 1- Means and standard deviations of $\Delta \mathrm{L}^{*}$ and $\Delta \mathrm{E}$ data for pigmented teeth after bleaching

\begin{tabular}{cccc}
\hline Dyes & Time & $\Delta \mathbf{L}^{*}$ & $\Delta \mathbf{E}$ \\
\hline CBSD & $10 \mathrm{~min}$ & $-1.78(0.58)^{\mathrm{abc}}$ & $4.11(0.64)^{\mathrm{b}}$ \\
& $1 \mathrm{~h}$ & $-2.47(0.98)^{\mathrm{a}}$ & $4.16(0.95)^{\mathrm{b}}$ \\
& $24 \mathrm{~h}$ & $-2.07(0.27)^{\mathrm{abc}}$ & $3.15(0.59)^{\mathrm{b}}$ \\
& $48 \mathrm{~h}$ & $-2.28(0.52)^{\mathrm{ab}}$ & $3.38(0.26)^{\mathrm{b}}$ \\
\hline Coffee & $72 \mathrm{~h}$ & $-1.05(0.58)^{\mathrm{bcd}}$ & $1.93(0.78)^{\mathrm{a}}$ \\
& $10 \mathrm{~min}$ & $-0.77(1.12)^{\mathrm{cd}}$ & $1.49(0.51)^{\mathrm{a}}$ \\
& $1 \mathrm{~h}$ & $-0.73(0.33)^{\mathrm{cd}}$ & $1.49(0.52)^{\mathrm{a}}$ \\
& $24 \mathrm{~h}$ & $-0.13(1.14)^{\mathrm{abc}}$ & $1.69(0.47)^{\mathrm{a}}$ \\
\hline
\end{tabular}

For each column, different superscript letters represent significant differences $(p<0.05)$. CBSD= cola-based soft drink 
not considered clinically undetectable.

\section{SCUSSION}

The hypothesis evaluated was rejected, since the teeth exposed to coffee showed $\Delta \mathrm{E}$ values smaller than 3.3 units for all times post-bleaching. There was a significant difference between teeth exposed to coffee and a CBSD for all times evaluated, except for teeth pigmented with a CBSD for $72 \mathrm{~h}$. Although coffee showed smaller pigmentation potential, it was still capable of causing clinically detectable color changes represented by $\Delta \mathrm{E}$ values higher than one unit. A different result was observed when bleached bovine teeth were exposed to coffee by Liporoni, et al. ${ }^{14}$ (2010), which observed no significant differences between the waiting times of 30 and 150 min post-bleaching when bovine teeth were whitened and then pigmented for 10 min with coffee and red wine ${ }^{13}$. According to these authors, coffee does not seem to cause staining after bleaching, while red wine was able to stain bleached enamel at 30 and 150 min after bleaching ${ }^{13}$.

In the present study two different solutions frequently consumed in daily life were selected as coloring agents. The CBSD has a low $\mathrm{pH}(\mathrm{pH} \approx 3)$ and higher erosive potential, which creates rougher enamel surfaces. Rougher surfaces associated with the pigments could be related to the CBSD's higher pigmentation potential. The instant coffee, on the other hand, has a higher $\mathrm{pH}(\mathrm{pH} \approx 5)$. Another difference between the two solutions may related to the size of staining particles since instant coffee tend to have larger particles, which could also explain its decreased pigmentation potential.

Colorimetry is the qualitative and quantitative measurement of color. Common color standards are: CMYK, RGB, HSL and CIE-Lab. For the evaluation of the color in teeth and other materials, various methods can be employed, such as the use of spectrophotometers, colorimeters and computerized image analysis ${ }^{2}$. In the present study, the spectrophotometer was used, providing greater accuracy for the measurements. According to Gehrke, et al. ${ }^{8}$ (2009), the spectrophotometer used in their work showed $82 \%$ accuracy between two consecutive measurements of the same specimen, while the colorimeter accounted for only $70 \%$. The device used in the present study employs a digital camera connected to a LED spectrophotometer that analyzes the tooth surface. This aspect may be an advantage considering the irregular buccal surfaces of bovine incisors. Moreover, according to the manufacturer, environmental aspects that may affect the visual perception do not influence the results obtained. The spectrophotometer shows the color reading on various parameters including

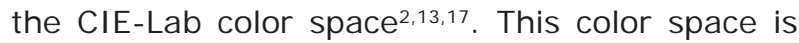

currently the most employed in dental research. The advantage of using the CIE-Lab color space is related to the calculation of the color variation $(\Delta E)$ from the variation of the coordinates $L^{*}, a^{*}$ and $\mathrm{b}^{*}$. As previously stated, from the $\Delta \mathrm{E}$ value one can make a comparison with a clinically observable color change $21,23,25$.

A concern related to the method was the standardization of all procedures. For this purpose, special care was taken at all times, from the selection of teeth and the temperature maintenance during bleaching to color readings. The choice of the middle third of teeth crowns as the area for the evaluation of color was determined by some possible variables that could alter the results. The elimination of the translucent area, the worn incisal and policromatic crown in their entirety was suggested to prevent interference in the color analysis. Other studies also use only the middle third of crowns to evaluate the color change in bleached teeth ${ }^{17}$.

The present study described a simple device designed to maintain the temperature and humidity during the bleaching procedure. This approach was chosen to replicate the clinical condition, and due to the fact that the great difference between the office room $\left(\approx 22^{\circ} \mathrm{C}\right)$ and oral cavity temperature (tooth) can certainly influence the reaction rate of the bleaching material. This same concern occurs when evaluating other clinical-related procedures such as adhesion to dentin and enamel. Moreover, the described device could be easily modified to fix samples for the evaluation cementation of posts on endodontically treated root canals. In such cases, a modification in the device to simulate the intrapulpal pressure would be interesting. In the present study the reservoir was filled with distilled water instead of saline solution or artificial saliva to standardize the water intake by teeth during the experiments.

Bovine teeth were used in this study due to several factors. The absence of carious lesions and good general condition should be considered for conducting such an experiment. The ease of obtaining bovine incisors was also decisive in the choice because human incisors with similar anatomy would be hard to find in sufficient numbers. As well, bovine teeth have similar physical chemistry to human teeth ${ }^{24}$ and supposedly provide similar results when whitening procedures and staining are evaluated ${ }^{2}$. Additionally, bovine teeth are often used in other studies, such as when evaluating the adhesion of resin-based materials to dental structures $^{5,7}$ and the wear and roughness ${ }^{19}$. It is important to note that by employing bovine teeth instead of human teeth, possible physical, chemical and morphological differences should be considered relevant when interpreting the results ${ }^{29}$. Another important aspect is related to the higher roughness of the buccal surface of sound bovine incisors, 
which could increase the staining capability, when compared to human incisors.

The roughness of the enamel is increased with whitening ${ }^{4,27}$, which could also contribute to staining after bleaching. Dahl and Pallensen ${ }^{6}$ (2003) suggested that this increased surface roughness caused by tooth whitening creates more susceptibility to extrinsic pigments. Moreover, intrinsic pigmentation is also boosted by the action of hydrogen peroxide ${ }^{3}$. It was observed that the predisposition to staining tends to be higher when the tooth is exposed to $35 \%$ hydrogen peroxide ${ }^{26}$. According to the results of this study, CBSD stained more than coffee. It is possible to suggest that this product, which has a low pH level, could stain more due to the increase of porosity of the surface provided by a potential demineralization of the tooth surface. Notably, along with the change in roughness, bleaching treatments have also been associated with decreased enamel hardness, but this change in hardness tends to reverse over time ${ }^{1}$. Therefore, it can be hypothesized that prolonged exposure to a CBSD after dental whitening could further increase enamel roughness and decrease hardness. In a similar way, it has been observed that toothbrushing immediately after dental bleaching may increase enamel roughness ${ }^{19}$ and that postponing oral hygiene for one or two hours after bleaching is advised ${ }^{20}$. It should be noted that if samples were stored in artificial saliva after bleaching, their ability of being stained could be reduced due to the potential remineralizing effect this solution.

There were significant differences between the times evaluated and none of the $\Delta \mathrm{E}$ values obtained was smaller than one unit. These data should be interpreted as a warning against absolute restrictions on substances containing the studied dyes. The data suggest that even $72 \mathrm{~h}$ after bleaching, there is still risk of pigmentation of teeth submitted to dental bleaching. Moreover, the pigmentation potential seems to be dependent on the coloring agent, more than on the time elapsed after bleaching. This idea is confirmed in the present study by the statistically significant interaction effects observed for both the $\Delta \mathrm{L}^{*}$ and $\Delta \mathrm{E}$ values. On the other hand, it would be interesting in the future to evaluate the post-bleaching waiting times using longer and shorter times of exposure to the dyes.

\section{CONCLUSI ONS}

Considering the limitations of this in vitro study, the data obtained suggest that:

The $\Delta \mathrm{E}$ value was dependent on the coloring agent with higher values being observed in the teeth pigmented with a cola-based soft drink.

Teeth pigmented with coffee presented $\Delta \mathrm{E}$ values below 3.3 for all times in the evaluation, but none of the $\Delta \mathrm{E}$ values obtained was considered clinically undetectable.

\section{ACKNOWLEDGMENTS}

The authors thank Mr. Fabio Grachiki for preparing the schematic drawing of the heating device used to maintain the teeth temperature and humidity, and Mr. Bruno Skronski Ton for his technical assistance during the experiment. The authors are also in debt of Laboratório de Prótese Odontológica Calgaro for providing the spectrophotometer employed in the present study.

\section{REFERENCES}

1- Abreu DR, Sasaki RT, Amaral FL, Florio FM, Basting RT. Effect of home-use and in-office bleaching agents containing hydrogen peroxide associated with amorphous calcium phosphate on enamel microhardness and surface roughness. J Esthet Restor Dent. 2011;23(3): 158-68.

2- Attia ML, Aguiar FH, Mathias P, Ambrosano GM, Fontes CM, Liporoni PC. The effect of coffee solution on tooth color during home bleaching applications. Am J Dent. 2009;22(3): 175-9.

3- Berger SB, Coelho AS, Oliveira VA, Cavalli V, Giannini M. Enamel susceptibility to red wine staining after $35 \%$ hydrogen peroxide bleaching. J Appl Oral Scie. 2008; 16(3):201-4.

4- Cavalli V, Arrais CA, Giannini M, Ambrosano GM. Highconcentrated carbamide peroxide bleaching agents effects on enamel surface. J Oral Rehabil. 2004;31(2): 155-9.

5- Cunha LF, Furuse AY, Mondelli RF, Mondelli J . Compromised bond strength after root dentin deproteinization reversed with ascorbic acid. J Endod. 2010;36(1): 130-4.

6- Dahl JE, Pallesen U. Tooth bleaching--a critical review of the biological aspects. Crit Rev Oral Biol Med. 2003; 14(4):292-304.

7- Furuse AY, Cunha LF, Moresca R, Paganeli G, Mondelli RF, Mondelli J . Enamel wetness effects on bond strength using different adhesive systems. Oper Dent. 2011;36(3):274-80.

8- Gehrke P, Riekeberg U, Fackler O, Dhom G. Comparison of in vivo visual, spectrophotometric and colorimetric shade determination of teeth and implant-supported crowns. Int J Comput Dent. 2009; 12(3): 247-63.

9- Gerlach RW. Tooth whitening clinical trials: a global perspective. Am J Dent. 2007; 20(Spec No A): 3A-6A.

10- Hattab FN, Qudeimat MA, al-Rimawi HS. Dental discoloration: an overview. J Esthet Dent. 1999;11(6):291-310.

11- Joiner A. The bleaching of teeth: a review of the literature. J Dent. 2006; 34(7):412-9.

12- Kumar A, Kumar V, Singh J, Hooda A, Dutta S. Druginduced discoloration of teeth: an updated review. Clin Pediatr. 2012; 51(2): 181-5.

13- Liporoni PC, Souto CM, Pazinatto RB, Cesar IC, Rego MA, Mathias $P$, et al. Enamel susceptibility to coffee and red wine staining at different intervals elapsed from bleaching: a photoreflectance spectrophotometry analysis. Photomed Laser Surg. 2010; (28 Suppl 2):S105-9.

14- Marshall K, Berry TG, Woolum J. Tooth whitening: current status. Compend Cont Educ Dent. 2010;31(7):486-92, 94-5.

15- Matis BA, Cochran MA, Eckert G. Review of the effectiveness of various tooth whitening systems. Oper Dent. 2009; 34(2):230-5. 16- Meireles SS, Heckmann SS, Leida FL, Santos IS, Della Bona A, Demarco FF. Efficacy and safety of $10 \%$ and $16 \%$ carbamide peroxide tooth-whitening gels: a randomized clinical trial. Oper Dent. 2008;33(6):606-12. 
17- Meireles SS, Santos IS, Bona AD, Demarco FF. A double-blind randomized clinical trial of two carbamide peroxide tooth bleaching agents: 2-year follow-up. J Dent. 2010;38(12):956-63.

18- Mondelli RF, Azevedo JF, Francisconi AC, Almeida CM, I shikiriama SK. Comparative clinical study of the effectiveness of different dental bleaching methods - two year follow-up. J Appl Oral Sci. 2012;20(4):435-43.

19- Mondelli RF, Azevedo JF, Francisconi PA, Ishikiriama SK, Mondelli J. Wear and surface roughness of bovine enamel submitted to bleaching. Eur J Esthet Dent. 2009; 4(4):396-403. 20- Navimipour EJ, Mohammadi N, Mostafazadeh S, Ghojazadeh M, Oskoee PA. Effect of delaying toothbrushing during bleaching on enamel surface roughness: an in vitro study. Oper Dent. 2013; 38(2): 218-25.

21- O'Brien WJ, Hemmendinger H, Boenke KM, Linger JB, Groh $\mathrm{CL}$. Color distribution of three regions of extracted human teeth. Dent Mater. 1997; 13(3): 179-85.

22- Publio JC, D'Arce MB, Brunharo NM, Ambrosano GM, Aguiar $\mathrm{FH}$, Lovadino JR, et al. Influence of surface treatments on enamel susceptibility to staining by cigarette smoke. J Clin Exp Dent. 2013;5(4): e163-8.

23- Ruyter IE, Nilner K, Moller B. Color stability of dental composite resin materials for crown and bridge veneers. Dent Mater. 1987; 3(5): 246-51.
24- Schilke R, Lisson J A, Bauss O, Geurtsen W. Comparison of the number and diameter of dentinal tubules in human and bovine dentine by scanning electron microscopic investigation. Arch Oral Biol. 2000; 45(5): 355-61.

25- Seghi RR, J ohnston WM, O'Brien WJ. Performance assessment of colorimetric devices on dental porcelains. J Dent Res. 1989;68(12): 1755-9.

26- Setien V, Roshan S, Cala C, Ramirez R. Pigmentation susceptibility of teeth after bleaching with 2 systems: an in vitro study. Quintessence Int. 2009;40(1):47-52.

27- Vasconcelos AA, Cunha AG, Borges BC, Vitoriano JO, AlvesJunior $C$, Machado $C T$, et al. Enamel properties after tooth bleaching with hydrogen/carbamide peroxides in association with a CPP-ACP paste. Acta Odontol Scand. 2012; 70(4): 337-43. 28- Xie P, Lu J, Wan H, Hao Y. Effect of toothpaste containing d-limonene on natural extrinsic smoking stain: a 4-week clinical trial. Am J Dent. 2010;23(4): 196-200.

29- Yassen GH, Platt JA, Hara AT. Bovine teeth as substitute for human teeth in dental research: a review of literature. J Oral Sci. $2011 ; 53(3): 273-82$. 